\title{
Um caso excepcional de miopericardite por Corynebacterium amycolatum
}

\section{An exceptional case of myopericarditis due to Corynebacterium amycolatum}

\author{
Elisa Meira, Catarina Canha, Carlos Costa, Rita Monteiro. \\ Serviço de Medicina Interna. Centro Hospitalar e Universitário de Coimbra. Coimbra. Portugal
}

\begin{abstract}
Resumo
As corinebactérias não difteróides têm uma prevalência crescente nos doentes hospitalizados, particularmente em doentes imunodeprimidos ou portadores de próteses artificiais ou dispositivos intravasculares. São responsáveis essencialmente pela infecção da pele cirúrgica e das estruturas cardíacas, provocando endocardite, miocardite e/ou pericardite, que necessitam de diagnóstico atempado e tratamento adequado. Apresentamos um caso clínico notável de miopericardite por Corynebacterium amycolatum, como sendo o primeiro caso relatado desta rara associação. Palabras clave. Miopericardite. Corynebacterium amycolatum. Idoso
\end{abstract}

\section{Introdução}

0 Corynebacterium amycolatum é um habitante normal da pele humana, comumente isolado nas amostras clínicas, mas frequentemente descartado como contaminante. Todavia, a sua prevalência está a aumentar nos doentes hospitalizados, nomeadamente em relação a infecção da pele cirúrgica, seguida dos Staphylococcus aureus ${ }^{1}$. São ainda descritas como causa de endocardite aguda (7,5-29\%), especialmente quando associada a doença cardíaca estrutural subjacente, a próteses valvulares ou catéteres intravasculares ${ }^{2,3}$. Contudo, até ao momento, não existe nenhum caso descrito na literatura

\begin{abstract}
The nondiphtheriae corynebacteria have an increasing prevalence in hospitalized patients, particularly in immunocompromised patients or those with prosthetic valves or intravascular devices. They are primarily responsible for the infection of surgical skin and cardiac structures, causing endocarditis, myocarditis and / or pericarditis, which require timely diagnosis and appropriate treatment. Here is a remarkable clinical case of Myopericarditis due to Corynebacterium amycolatum, being the first reported case of this rare association.
\end{abstract}

Key words. Myopericarditis. Corynebacterium amycolatum. Elderly

sobre a associação de corinebactéria com miopericardite, 0 que torna este caso particularmente relevante para ilucidar o impacto clínico deste gérmen.

\section{Caso Clínico}

0 caso clínico refere-se a uma doente do sexo feminino, 82 anos de idade, seguida na consulta de Medicina Interna, que em Janeiro de 2011, apresentava queixas de ortopneia, dispneia para pequenos esforços, associado a toracalgia atípica, de carácter intermitente, astenia, temperatura sub-febril e palpitações com 1 mês de evolução. Tinha antecedentes de insuficiência cardíaca, angina instável submetida a cateterismo cardíaco dois anos antes, bócio multinodular mergulhante e hipertensão arterial. Ao exame

Figura 1. Tomografia por emissão de positrões (PET): hipermetabolismo das paredes cardíacas, com atingimento pericárdico.

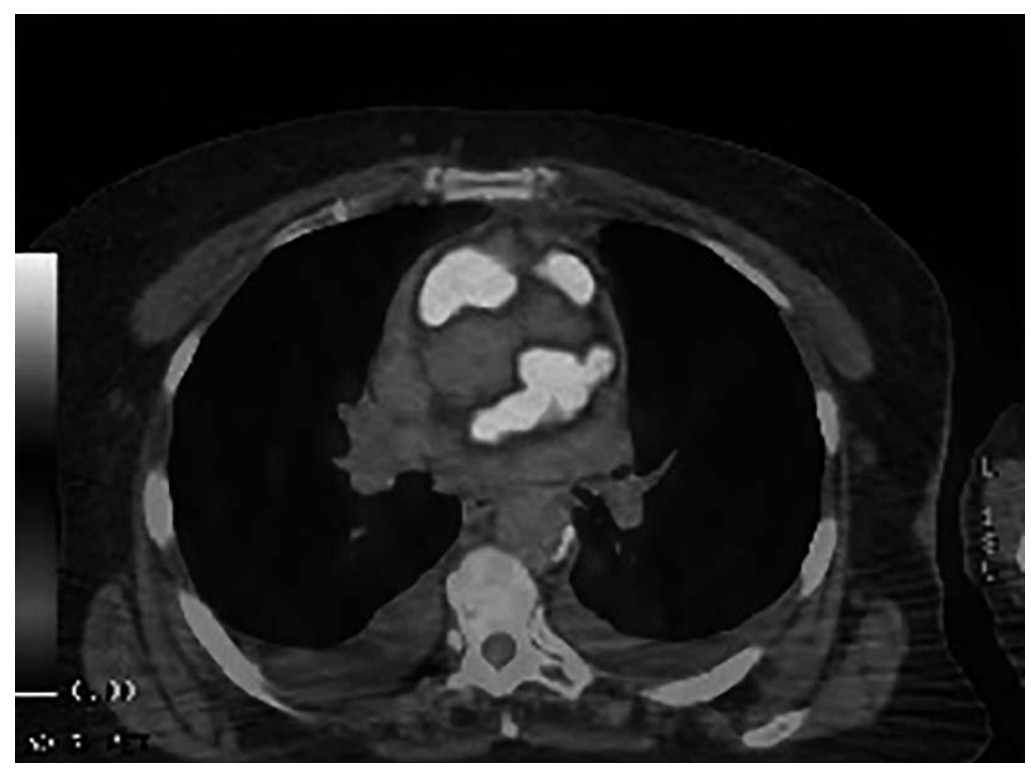


objectivo, apresentava diminuição do murmúrio vesicular em ambas as bases pulmonares com fervores bibasais e edema dos membros inferiores. A radiografia torácica mostrava reforço broncovascular bilateral. Realizou tomografia computorizada (TC) torácica que revelou a presença de nódulos pulmonares, o maior no lobo superior direito com $1 \mathrm{~cm}$. Para melhor esclarecimento da natureza desses nódulos pulmonares, efectuou tomografia por emissão de positrões (PET) que não identificou os referidos nódulos, porém constatou presença de miopericardite (Figura 1). 0 electrocardiograma e ecocardiograma realizados em ambulatório, há cerca de 1 mês, eram normais. A doente foi internada para estudo. Analiticamente, apresentava discreto aumento da proteina-C-reactiva, sem leucocitose e marcadores da necrose miocárdica negativos. 0 estudo serológico, culturas e pesquisa de BK foram negativos. A intra-dermorreacção foi negativa. No electrocardiograma tinha um ritmo sinusal, com infra-desnivelamento do segmento ST em V2 a V6. 0 ecocardiograma realizado no internamento revelou compromisso severo da função sistólica global do ventrículo direito, verificando-se paredes ventriculares e auriculares de aspecto restritivo ou infiltrativo. Realizou ressonância magnética cardíaca (Figura 2), que revelou marcado espessamento das estruturas epicárdicas, com envolvimento pericárdico, exercendo efeito de massa sobre as paredes auricular e ventricular, com infiltração do miocárdio adjacente. Foi submetida a biópsia do pericárdio no Serviço de Cardio-Torácica que revelou histopatologicamente a presença de pericardite colagenizante, cuja cultura foi positiva para Corynebacterium amycolatum. Apresentava também na cultura do exsudato da ferida cirúrgica um Enterococcus faecalis, optando-se pela associação de ampicilina ao linezolide por via intravenosa durante 3 semanas e posteriormente pela amoxicilina durante 3 semanas. Foi feita optimização da terapêutica para a insuficiência cardíaca e iniciou prednisolona $20 \mathrm{mg} / \mathrm{dia}$, com desmame progressivo, e colchicina $1 \mathrm{mg} /$ dia. Verificou-se alguma melhoria clínica, mantendo diminuição do murmúrio vesicular na base pulmonar esquerda, fervores na base pulmonar esquerda, mas sem edemas nos membros inferiores, com melhoria acentuada do aspecto infiltrativo das cavidades direitas no ecocardiograma. Várias complicações ocorreram durante 0 tratamento da miopericardite, nomeadamente, colite pseudomembranosa, 1 mês após $01^{\circ}$ internamento, e tromboembolia pulmonar, 3 meses depois, com recuperação parcial da capacidade funcional. Ponderamos a realização de cateterismo para esclarecimento diagnóstico da hipótese de pericardite constritiva, mas por recusa da doente, optamos pela terapêutica conservadora, mantendo em vigilância na consulta. Contudo, 7 meses depois, surgiu nova descompensação da insuficiência cardíaca, refractária ao tratamento médico, acabando a doente por falecer no $5^{\circ}$ dia de internamento.

Figura 2. Ressonância magnética cardíaca: marcado espessamento das estruturas epicárdicas, com envolvimento pericárdico, exercendo efeito de massa sobre as paredes auricular e ventricular, com infiltração do miocárdio adjacente.

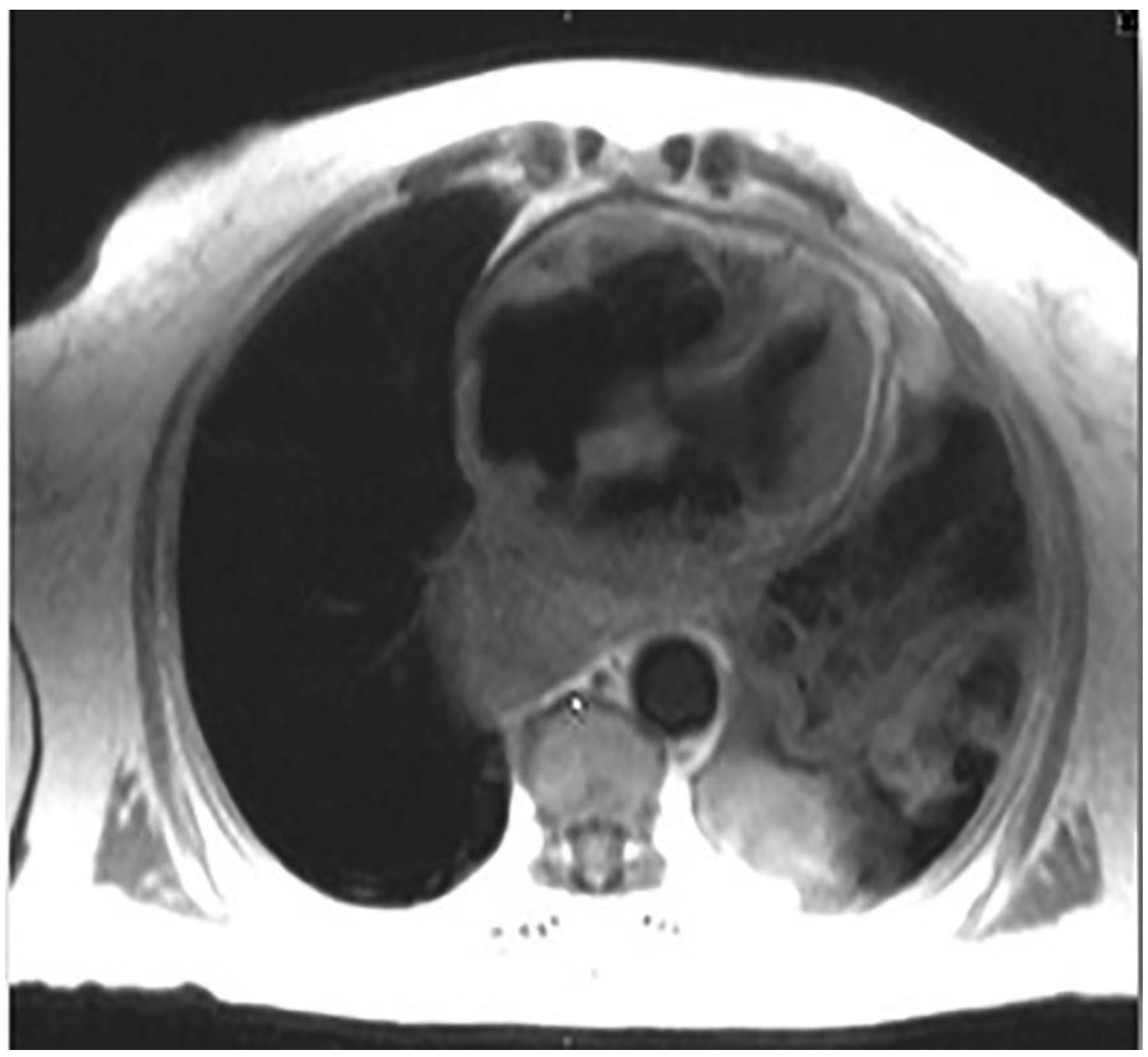




\section{Discussão}

Este caso destaca-se pela complexidade do diagnóstico e tratamento da miopericardite numa doente idosa com múltiplas co-morbilidades. A miopericardite foi um achado imagiológico da PET, inicialmente efectuado para esclarecimento diagnóstico dos nódulos pulmonares, mas que desapereceram. Provavelmente se tratavam de infiltrados nodulares derivados de edema pulmonar por insuficiência cardíaca. A destacar ainda que, 0 isolamento da Corynebacterium amycolatum exige uma técnica de ampliação especial por ser um colonizador habitual. A sua identificação foi possível através do cartão de identificação ANC do sistema Vitek® 2, destinado para bactérias anaeróbias e corineformes. 0 teste de sensibilidade a antibióticos, revelou sensibilidade a ampicilina, amoxicilina/àcido clavulânico, impenem, vancomicina e tobramicina; e resistência a eritromicina, ciprofloxacina, trimetoprim/sulfametoxazol. A debilidade física progressiva da doente tornou-se num factor preponderante na escolha das abordagens terapêuticas. Apesar da resposta razoável ao tratamento da miopericardite, este foi interrompido devido a posteriores complicações, que condicionaram bastante o prognóstico da doente, mantendo-se apenas a colchicina. A confirmação histopatológica da existência de pericardite exige a realização de biópsia pericárdica, que não deve ser realizada na ausência de disfunção ventricular sistólica ou de sintomas de insuficiência cardíaca ${ }^{4,5}$. Em alguns casos, a miopericardite pode evoluir para pericardite constritiva, exigindo uma cirurgia agressiva, complicada de realizar em doentes idosos e debilitados. De facto, trata-se do primeiro e único caso descrito na literatura de miopericardite causada por Corynebacterium amycolatum. Salienta-se que este gérmen afecta sobretudo mulheres, indivíduos imunodeprimidos ou portadores de próteses artificiais ou dispositivos intravasculares. Além da dificuldade de isolamento deste organismo, a complexidade da abordagem terapêutica foi um dos factos determinantes do caso, assim como a impossibilidade de previsão prognóstica da doença, uma vez que existem poucos dados publicados desta entidade clínica rara e desafiante

\section{Referências bibliográgicas}

1. Rizvi M, Rizvi MW, Shaheen, Sultan A, Khan F, Shukla I, Malik A. Emergence of coryneform bacteria as pathogens in nosocomial surgical site infections in a tertiary care hospital of North India. J Infect Public Health 2013; 6 (4):283-8

2. Dalal A, Urban C, Segal-Maurer S. Endocarditis due to Corynebacterium amycolatum. J Med Microbiol October 2008; 57 (10):1299-302

3. Knox KL, Holmes AH. Nosocomial Endocarditis Caused by Corynebacterium amycolatum and Other Nondiphtheriae Corynebacteria. Emerg Infect Dis. 2002; 8(1): 97-9.

4. Maisch B, Seferovic PM, Ristic AD, et al. Guidelines on the Diagnosis and Management of Pericardial Diseases Executive Summary. The Task Force on the Diagnosis and Management of Pericardial Diseases of the European Society of Cardiology. Eur Heart J 2004:25 (7): 587-610.

5. Imazio M and Trinchero R. Myopericarditis: Etiology, management, and prognosis. Int J Cardiol 2008; 23:127. 